\title{
Scour from the interstitial spaces in cobble-bed rivers
}

\author{
V Jonker ${ }^{1 *}$ and A Rooseboom ${ }^{2}$ \\ ${ }^{1}$ Ninham Shand, PO Box 1347, Cape Town 8000, South Africa \\ ${ }^{2}$ Department of Civil Engineering, University of Stellenbosch, Private Bag X1, Matieland 7602, South Africa
}

\begin{abstract}
The periodic removal of sand from the interstitial spaces between cobbles is extremely important for ecosystem functioning in cobble-bed rivers. In order to flush fine sediments from the interstitial spaces between cobbles in river reaches downstream of dams, specific dam releases known as flushing flows or sediment maintenance flows are utilised. This paper describes the development and calibration of a mathematical model to predict the equilibrium depth of scour of fine sands from between cobbles in terms of applied stream power principles. The model was developed with the aid of physical model experiments and is founded on a stream power model which defines the condition of dynamic equilibrium in a deformed sand-bed river. Calibration was done in the laboratory under clear water conditions and with uniform cobble sizes. The scouring of fine sands in cobble-bed rivers is associated with an increase in absolute bed roughness and an associated decrease in the unit stream power applied along the bed as the cobbles become exposed. When scour ceases, the sand particles on the bed are at the movement threshold and critical conditions exist. In order to establish the relationship between equilibrium scour depth and bed particle characteristics, the power which is required to suspend sand particles under laminar boundary conditions is equated with the turbulent power being applied along the bed.
\end{abstract}

Keywords: cobble-bed, interstitial spaces, flushing flows, stream power, scour depth, environmental flow requirements

\section{Introduction}

In cobble-bed rivers, many aquatic species are dependent on the interstitial spaces between the cobbles for their survival. Salmonids, for example, use these spaces for laying their eggs while the spaces also provide habitat and sheltering for various benthic insects (Gordon et al., 1992). The accumulation of fine sediments in cobble-bed rivers, which fill these interstitial spaces, can have a detrimental effect on the whole aquatic ecosystem and scouring of the interstitial sand from cobble beds is seen as the single most important substrate maintenance process for river biota (Hirschowitz et al., 2007). Natural phenomena such as catchment erosion may lead to sediment loads being introduced and deposited on cobble river beds, but natural floods ensure the periodic removal thereof. The construction of a dam, however, leads to a decrease in flood peaks, flood frequency and sediment transport capacity in the river channel downstream and fine sediments introduced into this part of the river system, either via the dam or from the downstream catchment, may accumulate on parts of the river bed.

In order to flush fine sediments from the interstitial spaces between cobbles downstream of dams, specific dam releases known as flushing flows or sediment maintenance flows are utilised. The range of effective flushing flows is relatively narrow. Whereas the rate and efficiency of fine sand removal increase with discharge, so does the cost if the released water is lost for storage, diversion or power generation. The transport rate of larger sized sediments also increases with discharge and may need to be kept within limits. The size of a flushing flow may be further constrained by the release capacity of the dam, financial

* To whom all correspondence should be addressed.

III +2721 481-2473; fax: +2721 424-5588;

e-mail: verno.jonker@shands.co.za

Received 16 October 2006; accepted in revised form 20 June 2008 and legal liabilities associated with the creation of an artificial flood as well as the availability of water at the appropriate time (Wilcock et al., 1996). In addition, the quantification of flushing flows is subject to uncertainty due to the complexity of flow and sediment transport mechanisms in cobble-bed rivers. Although there is a clear need to specify flushing flows as accurately as possible, relatively crude methods are often used due to a lack of appropriate models. These include the specification of discharges with a certain return period or methods based on complicated estimates of critical shear stress in mixed size sediments (Reiser et al., 1989).

Ligon et al. (1995) and Kondolf and Wilcock (1996) noted that the goals of flushing flows need to be stated in terms of measurable changes to the physical habitat rather than the abundance of organisms. In line with this philosophy, this paper addresses flushing flows in terms of a sand scour model which is founded on the law of conservation of stream power and which defines the relationship between discharge and the absolute depth of scour of fine sands from between cobbles.

\section{Sediment transport and the principle of least applied power}

The law of conservation of power, which is defined in scalar terms and directly related to time, is a third derivative of Newton's second law together with the laws of conservation of energy and momentum. This law has been found to provide good insight into the sediment transport characteristics of rivers and is defined by Rooseboom (1974) under conditions of steady, turbulent uniform flow as:

$$
\begin{aligned}
& \int_{y_{0}}^{D} \rho g s v d y=\int_{y_{0}}^{D} \tau \frac{d v}{d y} d y \\
& \text { where: } \\
& \qquad \quad=\text { fluid density }\left(\mathrm{kg} / \mathrm{m}^{3}\right)
\end{aligned}
$$




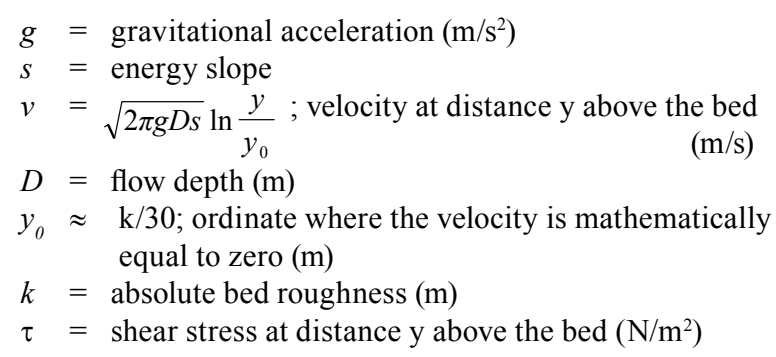

The term $\rho g s v$ in Eq. (1) represents the amount of unit power made available by a flowing river, whereas $\tau \frac{d v}{d y}$ represents the power applied per unit volume to maintain motion.

\section{The threshold condition}

Based on the hypothesis that where alternative modes of flow exist, that mode of flow which requires the least amount of unit power will be followed, it follows that fluid flowing over movable material would only transport the material, if it will result in a decrease in the amount of unit power being applied (Rooseboom, 1998). As the power applied along the bed of a river varies depending on whether laminar or turbulent flow conditions prevail at the bed, the critical condition for sediment movement also depends on whether the flow at the bed is laminar or turbulent. The applied power required per unit volume to suspend a particle with density $\rho_{\mathrm{s}}$ and settling velocity $\mathrm{V}_{\mathrm{ss}}$ in a fluid with density $\rho$, equals (Rooseboom, 1992):

$$
\left(\rho_{s}-\rho\right) g V_{s s}
$$

Stokes's law (Graf, 1971) defines the settling velocity of a particle with diameter $\mathrm{d}$ under viscous conditions as:

$$
d^{2} g \frac{\rho_{s}-\rho}{18 \rho v}
$$

where:

$$
v=\text { kinematic viscosity }\left(\mathrm{m}^{2} / \mathrm{s}\right)
$$

Under conditions of turbulent flow, the settling velocity as expressed by Graf (1971) equals:

$$
\sqrt{\frac{4\left(\rho_{s}-\rho\right) g d}{3 \rho C_{d}}}
$$

where:

$$
C_{d}=\begin{aligned}
& \text { drag coefficient (assumed constant for larger } \\
& \text { diameters) }
\end{aligned}
$$

Under conditions of laminar or smooth turbulent flow, Rooseboom (1974) showed that the unit stream power applied along the bed equals:

$$
\frac{(\rho g s D)^{2}}{\rho v}
$$

The critical condition for the movement of sediment particles is reached when the power applied along the bed exceeds the power required to suspend the sediment particles. From Eqs. (2), (3) and (5) a relationship defining the threshold for sediment transport under viscous conditions can be defined. This relationship, calibrated with data by Grass (1970) and Yang (1973), is found to be:

$$
\frac{\sqrt{g D s}}{V_{s s}}=\frac{1.6 v}{\sqrt{g D s} d}
$$

for values of $\sqrt{g D s} d<13$, i.e. with smooth turbulent or completely laminar flow over a smooth bed (Rooseboom, 1992).
Under conditions of rough turbulent flow, Rooseboom (1992) showed that the unit applied power along a bed of particles with diameter $d$ is:

$$
\approx \frac{30 \rho_{s s} D \sqrt{2 \pi g s} D}{d}
$$

From Eqs. (2), (4) and (7) therefore, the critical condition for the movement of sediment along an even bed in rough turbulent flow is defined by:

$$
\frac{\sqrt{g D s}}{V_{s s}}=\text { Constant }
$$

This relationship was calibrated with measured data from Yang (1973) and the value of the constant was found to be 0.12 for values of $\frac{\sqrt{g D s} d}{v}>13$ (Rooseboom, 1992).

\section{Dynamic equilibrium and sand-bed deformation}

Equation (7), which represents the amount of stream power applied along a bed under conditions of rough turbulent flow, can also be re-written as:

$$
\left(\tau \frac{d v}{d y}\right)_{0}=\frac{14.8 \rho g s D \sqrt{2 \pi g s D}}{R_{0}}
$$

where:

$$
R_{0} \approx d / 2 \text {; the radius of a turbulent eddy next to the bed (m) }
$$

From Eq. (9), and based on the concept of minimum applied power, it is evident that once the threshold condition for sediment movement is exceeded a further reduction in the amount of unit turbulent stream power applied along an alluvial bed is possible by means of various mechanisms (Rooseboom, 1974). One of these mechanisms entails the formation of bed forms, i.e. ripples, dunes, etc., which result in an increase in the value $\mathrm{R}_{0}$.

Furthermore, it can be shown (Rooseboom, 1992) that the sediment concentration at any level within a stream is directly proportional to (applied power) ${ }^{\mathrm{z}}$ and subsequently that the sediment-carrying capacity of a stream is directly proportional to (applied power along the bed) ${ }^{z}$, with $z$ defined as:

$$
z=\frac{5 \sqrt{2 \pi} V_{s s}}{6 \sqrt{g D s}}
$$

It therefore follows that, as an alluvial river reduces the amount of unit stream power applied along its bed through deformation of the bed, the river is effectively decreasing its sediment-carrying capacity - a process which continues until a condition is reached where the sizes of the boundary eddies that fit in with the bed forms become so large that the average rate of deposition of particles is equal to their average rate of re-suspension. At this point, the river is in a state of steady sediment transport or dynamic equilibrium. Under these conditions, with particles on the bed being entrained and deposited at the same rate, it is obvious that critical hydraulic conditions must prevail at the bed where individual particles are continually crossing the movement threshold. However, it has been observed that it is not possible to have sand particles of less than about $2 \mathrm{~mm}$ in diameter at rest under turbulent boundary conditions on an even bed, as the absolute bed roughness is too small to induce a turbulent boundary layer (Rooseboom, 1974). It therefore follows that at the point of dynamic equilibrium along a deformed sand-bed river, critical conditions for sediment movement prevail at and below an interface between a thin laminar boundary layer along the bed and turbulent eddies above. This was confirmed by Rooseboom and Le Grange (1994) who, based on an analysis of recorded flood levels and scour depths, concluded that contrary to conventional wisdom, laminar boundary conditions come into play when equilibrium conditions are approached at the 
flood peak. The applied turbulent unit stream power at the bed, expressed in terms of the absolute bed roughness, must therefore be proportional to the unit power which is required to bring particles into suspension under laminar conditions (Rooseboom and Le Grange, 1994). From Eqs. (2) and (3), the unit stream power required to suspend particles under laminar boundary conditions is directly proportional to:

$$
\frac{\left(\rho_{s}-\rho\right)^{2} g^{2} d^{2}}{\rho v}
$$

In similar fashion, from Eq. (7), the unit stream power applied in maintaining motion along a river bed under turbulent flow conditions is approximately equal to:

$$
\frac{30 \rho g s D \sqrt{2 \pi g s D}}{k}
$$

where

$$
k=\text { absolute bed roughness }
$$

From Eqs. (11) and (12):

$$
\frac{30 \rho_{s s} D \sqrt{2 \pi g s D}}{k} \alpha \frac{\left(\rho_{s}-\rho\right)^{2} g^{2} d^{2}}{\rho v}
$$

which simplifies to:

$$
\frac{\sqrt{g D s}}{V_{s s}}=\left[\frac{\sqrt{g D s} k}{\sqrt{2 \pi} v}\right]^{1 / 2} \text { Constant }\left[\frac{v}{\sqrt{g D s} d}\right]
$$

A comparison of Eq. (13), which represents the condition of dynamic equilibrium in a deformed sand-bed river and defines the relationship between absolute bed roughness, particle characteristics and bed deformation, and Eq. (6), which represents critical conditions for sediment movement in laminar flow, reveals that the two equations are similar, except for the additional term $\left.\frac{\sqrt{g D s} k}{\sqrt{2}}\right]^{1 / 2}$ in Eq. (13). Rooseboom and Le Grange (2000) calibrated Eq. (13) with available data on sand-bed deformation under conditions of dynamic equilibrium. Their findings confirmed that, contrary to conventional wisdom, a laminar boundary layer comes into play at equilibrium conditions in a deformed sandbed river. They also concluded that the term $\left.\frac{\sqrt{g D s} k}{\sqrt{2 \pi} v}\right]^{1 / 2}$, referred to as delta $(4)$, represents the decrease in applied stream power due to deformation of the bed, with $\mathrm{k}$, the absolute bed roughness, reflecting the size of the boundary eddies that fit in with the changing bed forms.

\section{A sand scour model for cobble-bed rivers}

The scouring of fine sediments from the interstitial spaces in a cobble river bed is associated with changes in absolute bed roughness as the cobbles become exposed during scouring. It is hypothesised that the process of fine sediment scouring in a cobble-bed river and the associated change in absolute bed roughness is similar to the process of bed deformation in a sand-bed river, except for the fact that the cobbles will limit the extent of bed deformation (see Fig. 1). Consequently, at a particular discharge, the relationship that exists between sand particle characteristics and the maximum depth of sand scour in a cobble-bed river would be similar to the relationship that exists between absolute bed roughness and particle characteristics under conditions of dynamic equilibrium on a deformed sand-bed river.

In order to evaluate the above hypothesis, laboratory studies were undertaken. During the laboratory experiments, various combinations of sand and cobble sizes were employed to develop relationships between applied power, particle characteristics and maximum scour depth.

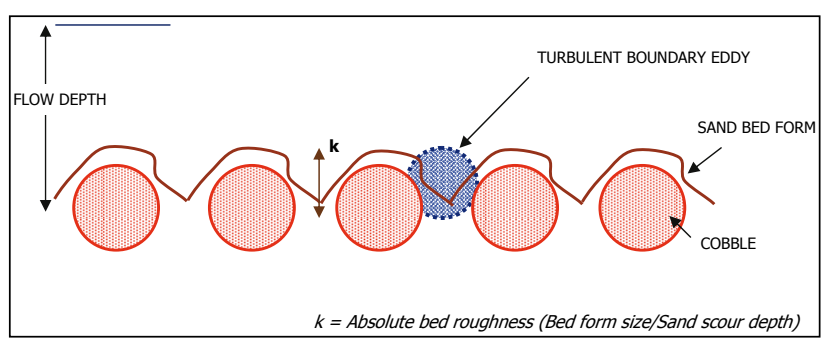

Figure 1

Schematic representation of similarities between cobble-bed sand scour and sand-bed deformation

\section{Experimental procedure}

Tests were performed in a horizontal flume of $1 \mathrm{~m}$ width and $40 \mathrm{~m}$ length in the hydraulics laboratory of the Department of Civil Engineering at the University of Stellenbosch. Cobbles were collected from rivers and sorted with a gravelometer. Two to three layers of uniform, spherical cobbles were arranged in a closely packed pattern in order to create an artificial cobble bed of approximately $2.4 \mathrm{~m}$ length. The cobbles were then completely covered with sand of a fairly uniform grading. At the upstream side of the cobble bed, a ramp of gravel and smaller cobbles was constructed to allow full development of the turbulent flow profile. Flow depths were controlled with an adjustable weir at the downstream end of the flume, which was also used for measuring discharge. Average velocities above the cobble bed were measured with an Ott-meter. The experiments focused on scour depths of up to one cobble diameter. In total, 50 experiments representing six different sand-cobble combinations were completed as shown in Table 1. The laboratory setup is shown diagrammatically in Fig. 2 (next page).

\begin{tabular}{|l|c|c|}
\hline \multicolumn{3}{|c|}{ TABLE 1 } \\
\hline Experiment & $\begin{array}{c}\text { Median sand } \\
\text { diameter (mm) }\end{array}$ & $\begin{array}{c}\text { Cobble diameter } \\
\text { (mm) }\end{array}$ \\
\hline I & 0.22 & 60 \\
\hline II & 0.22 & 71 \\
\hline III & 0.22 & 130 \\
\hline IV & 0.54 & 80 \\
\hline V & 0.54 & 130 \\
\hline VI & 0.83 & 60 \\
\hline
\end{tabular}

After preparation of the sand-covered cobble bed, the following basic procedure was followed:

- With the adjustable downstream weir controlling the water level in the flume, water was allowed to fill the flume very slowly in such a way that no sand movement took place along the cobble bed

- The water supply to the flume was slowly increased until the desired discharge was obtained. The discharge was calculated from the water level at the downstream weir and was verified with velocity and depth measurements above the cobble bed. A large enough depth was maintained above the cobble bed to ensure that no sand movement took place.

- The adjustable weir was rapidly lowered until the desired water depth above the experimental cobble-bed area was reached. This represented the start of the experiment.

- At pre-determined positions along the bed, the level of the sand (depth of scour) was measured as the experiment pro- 


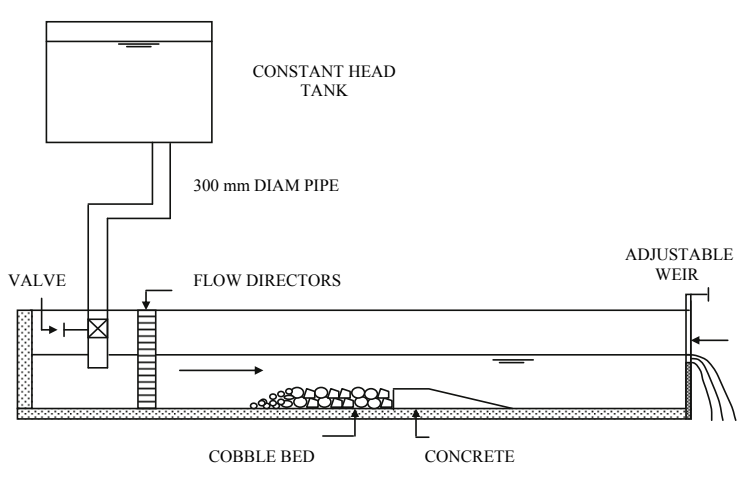

Figure 2

Laboratory set-up

gressed until no further change in the scour level could be observed.

Due to the relatively short length of the cobble bed within the flume, it was not possible to measure the difference in water levels between the upstream and downstream sections of the experimental cobble-bed reach accurately. As the flow depth above the cobble bed was controlled by the downstream weir, the flow in the flume was slightly non-uniform. Based on the procedure for calculating the energy slope under conditions of gradually varied flow, the Chézy formula was used to calculate the energy slope above the cobblebed area based on the measured average flow velocity. Due to the large difference in resistance between the cobble bed of the flume and the glass sidewalls, it was assumed that flow resistance along the centreline would be affected only slightly by the sidewalls and the hydraulic radius in the Chézy equation was substituted with the flow depth above the cobble bed. The scour depth beneath the top of the cobbles was used to represent the absolute roughness $(k)$ in the Chézy equation. In order to limit the uncertainty associated with large-scale roughness, the ratio of flow depth to absolute roughness was maintained at values above three throughout the experiments. Jonker (2002) provides a detailed description of the experimental procedure.

A summary of the experimental data is included as Table 2 .

\section{Laminar boundary conditions}

In order to gain insight into the hydraulic conditions that existed at the experimental cobble bed when the maximum level of sand scour was reached, the laboratory data were analysed in terms of $\frac{\sqrt{g D s}}{V}$ and $\frac{\sqrt{g D s} d}{}$, which define the movement threshold ${ }^{V^{s s}}$ for cohesionless sediment particles under both laminar and turbulent boundary conditions. The energy gradients in the above terms were calculated based on an absolute roughness equivalent to the maximum scour depth that was reached below the top of the cobble crests, while $\mathrm{V}_{\mathrm{ss}}$ was calculated as the settling velocity of the sand particles (with diameter d) under laminar conditions, i.e. by means of Eq. (3).

Figure 3 shows the results of the experimental analysis superimposed on the modified Liu curve (Liu, 1957). It shows that cobble-bed scour data with

\begin{tabular}{|c|c|c|c|c|c|c|c|}
\hline \multicolumn{8}{|c|}{$\begin{array}{c}\text { TABLE } 2 \\
\text { Experimental data }\end{array}$} \\
\hline Setup & $\begin{array}{c}\text { Median } \\
\text { sand } \\
\text { diam }\end{array}$ & $\begin{array}{c}\text { Cobble } \\
\text { diam. }\end{array}$ & $\begin{array}{l}\text { Flow } \\
\text { depth }\end{array}$ & $\begin{array}{l}\text { Dis- } \\
\text { charge }\end{array}$ & $\begin{array}{l}\text { Veloc- } \\
\text { ity }\end{array}$ & $\begin{array}{l}\text { Energy } \\
\text { slope }\end{array}$ & $\begin{array}{l}\text { Scour } \\
\text { depth }\end{array}$ \\
\hline & $(\mathrm{mm})$ & $(\mathrm{mm})$ & (m) & $\left(\mathrm{m}^{3} / \mathrm{s}\right)$ & $(\mathrm{m} / \mathrm{s})$ & - & $(\mathrm{mm})$ \\
\hline \multirow{13}{*}{ I } & 0.22 & 60 & 0.400 & 0.200 & 0.500 & \begin{tabular}{|l|l|}
0.0002 \\
\end{tabular} & 8 \\
\hline & 0.22 & 60 & 0.071 & 0.025 & 0.354 & 0.0018 & 15 \\
\hline & 0.22 & 60 & 0.600 & 0.300 & 0.500 & 0.0002 & 15 \\
\hline & 0.22 & 60 & 0.200 & 0.100 & 0.500 & 0.0011 & 30 \\
\hline & 0.22 & 60 & 0.500 & 0.300 & 0.600 & \begin{tabular}{|l|l|}
0.0004 \\
\end{tabular} & 30 \\
\hline & 0.22 & 60 & 0.600 & 0.400 & 0.667 & 0.0004 & 40 \\
\hline & 0.22 & 60 & 0.800 & 0.600 & 0.750 & \begin{tabular}{|l|}
0.0004 \\
\end{tabular} & 40 \\
\hline & 0.22 & 60 & 0.300 & 0.200 & 0.667 & 0.0013 & 45 \\
\hline & 0.22 & 60 & 0.800 & 0.500 & 0.625 & 0.0003 & 45 \\
\hline & 0.22 & 60 & 0.250 & 0.200 & 0.800 & 0.0027 & 60 \\
\hline & 0.22 & 60 & 0.400 & 0.300 & 0.750 & \begin{tabular}{|l|}
0.0012 \\
\end{tabular} & 60 \\
\hline & 0.22 & 60 & 0.500 & 0.400 & 0.800 & 0.0010 & 60 \\
\hline & 0.22 & 60 & 0.600 & 0.500 & 0.833 & 0.0008 & 60 \\
\hline \multirow{6}{*}{ II } & 0.22 & 71 & 0.201 & 0.099 & 0.494 & 0.0011 & 36 \\
\hline & 0.22 & 71 & 0.400 & 0.200 & 0.500 & 0.0004 & 36 \\
\hline & 0.22 & 71 & 0.804 & 0.502 & 0.624 & \begin{tabular}{|l|}
0.0003 \\
\end{tabular} & 53 \\
\hline & 0.22 & 71 & 0.299 & 0.200 & 0.669 & 0.0016 & 71 \\
\hline & 0.22 & 71 & 0.601 & 0.403 & 0.671 & 0.0006 & 71 \\
\hline & 0.22 & 71 & 0.600 & 0.499 & 0.832 & \begin{tabular}{|l}
0.0009 \\
\end{tabular} & 71 \\
\hline \multirow{4}{*}{ III } & 0.22 & 130 & 0.235 & 0.120 & 0.511 & 0.0010 & 36 \\
\hline & 0.22 & 130 & 0.268 & 0.160 & 0.597 & 0.0013 & 53 \\
\hline & 0.22 & 130 & 0.340 & 0.243 & 0.715 & \begin{tabular}{|l|}
0.0014 \\
\end{tabular} & 64 \\
\hline & 0.22 & 130 & 0.399 & 0.390 & 0.977 & \begin{tabular}{|l|}
0.0029 \\
\end{tabular} & 121 \\
\hline \multirow{9}{*}{ IV } & 0.54 & 80 & 0.200 & 0.109 & 0.545 & \begin{tabular}{|l|l|}
0.0012 \\
\end{tabular} & 29 \\
\hline & 0.54 & 80 & 0.273 & 0.226 & 0.828 & 0.0023 & 49 \\
\hline & 0.54 & 80 & 0.406 & 0.237 & 0.584 & \begin{tabular}{|l|}
0.0005 \\
\end{tabular} & 28 \\
\hline & 0.54 & 80 & 0.278 & 0.256 & 0.921 & \begin{tabular}{|l|}
0.0031 \\
\end{tabular} & 59 \\
\hline & 0.54 & 80 & 0.567 & 0.333 & 0.587 & \begin{tabular}{|l|}
0.0004 \\
\end{tabular} & 36 \\
\hline & 0.54 & 80 & 0.405 & 0.387 & 0.956 & \begin{tabular}{|l|}
0.0017 \\
\end{tabular} & 46 \\
\hline & 0.54 & 80 & 0.448 & 0.346 & 0.772 & \begin{tabular}{|l|}
0.0009 \\
\end{tabular} & 45 \\
\hline & 0.54 & 80 & 0.698 & 0.525 & 0.752 & 0.0005 & 42 \\
\hline & 0.54 & 80 & 0.374 & 0.465 & 1.243 & \begin{tabular}{|l|}
0.0042 \\
\end{tabular} & 80 \\
\hline \multirow{6}{*}{ V } & 0.54 & 130 & 0.289 & 0.162 & 0.561 & \begin{tabular}{|c|}
0.0010 \\
\end{tabular} & 53 \\
\hline & 0.54 & 130 & 0.308 & 0.236 & 0.766 & \begin{tabular}{|l|}
0.0020 \\
\end{tabular} & 71 \\
\hline & 0.54 & 130 & 0.339 & 0.332 & 0.979 & \begin{tabular}{|l|}
0.0033 \\
\end{tabular} & 95 \\
\hline & 0.54 & 130 & 0.321 & 0.186 & 0.579 & \begin{tabular}{|l|}
0.0008 \\
\end{tabular} & 41 \\
\hline & 0.54 & 130 & 0.320 & 0.228 & 0.713 & \begin{tabular}{|l}
0.0015 \\
\end{tabular} & 63 \\
\hline & 0.54 & 130 & 0.399 & 0.530 & 1.328 & \begin{tabular}{|l|l|}
0.0054 \\
\end{tabular} & 122 \\
\hline \multirow{12}{*}{ VI } & 0.83 & 60 & 0.305 & 0.200 & 0.656 & 0.0008 & 20 \\
\hline & 0.83 & 60 & 0.499 & 0.295 & 0.592 & \begin{tabular}{|l|}
0.0004 \\
\end{tabular} & 20 \\
\hline & 0.83 & 60 & 0.703 & 0.505 & 0.718 & \begin{tabular}{|l|}
0.0003 \\
\end{tabular} & 20 \\
\hline & 0.83 & 60 & 0.400 & 0.295 & 0.738 & \begin{tabular}{|l|}
0.0009 \\
\end{tabular} & 30 \\
\hline & 0.83 & 60 & 0.599 & 0.394 & 0.658 & \begin{tabular}{|l|}
0.0004 \\
\end{tabular} & 30 \\
\hline & 0.83 & 60 & 0.601 & 0.505 & 0.841 & \begin{tabular}{|l|}
0.0006 \\
\end{tabular} & 30 \\
\hline & 0.83 & 60 & 0.501 & 0.394 & 0.786 & 0.0008 & 40 \\
\hline & 0.83 & 60 & 0.709 & 0.600 & 0.846 & \begin{tabular}{|l|l|}
0.0006 \\
\end{tabular} & 40 \\
\hline & 0.83 & 60 & 0.397 & 0.394 & 0.992 & \begin{tabular}{|l|}
0.0019 \\
\end{tabular} & 45 \\
\hline & 0.83 & 60 & 0.502 & 0.505 & 1.006 & \begin{tabular}{|l|}
0.0014 \\
\end{tabular} & 45 \\
\hline & 0.83 & 60 & 0.303 & 0.295 & 0.973 & \begin{tabular}{|l|}
0.0030 \\
\end{tabular} & 60 \\
\hline & 0.83 & 60 & 0.603 & 0.600 & 0.995 & \begin{tabular}{|l|}
0.0012 \\
\end{tabular} & 60 \\
\hline
\end{tabular}

similar values of $\Delta$, representing absolute bed roughness at the point of maximum scour, display the same pattern as that displayed by the curved section of the modified Liu Curve, which represents critical conditions for cohesionless sediment particles smaller than $2 \mathrm{~mm}$ on an even bed with laminar boundary layer conditions (Rooseboom, 1992). Figure 3 therefore suggests that similar to Rooseboom and Le Grange's (2000) findings related to dynamic equilibrium in a sand-bed river, the condition of maximum sand scour in a cobble bed goes hand in hand with critical conditions for sediment movement and the formation of a laminar sublayer below the turbulent eddies that fit in with the exposed cobbles.

\section{The maximum depth of scour}

As a further test of the hypothesis that the process of sand scouring in a cobble-bed river and the associated change in absolute bed roughness is 
similar to the process of bed deformation in a sand-bed river, the results of the cobble-bed sand scour experiments were superimposed on a diagram which represents the full spectrum of bed conditions in a sand-bed river, from lower regime to upper regime, within a single system (Fig. 4). This diagram was developed by Rooseboom and Le Grange (1994) based on the theory of dynamic equilibrium. It displays the typical progression of equilibrium conditions in a sand-bed river for three sand particle diameters and shows that, for any particular sand particle diameter, as the value of $\frac{\sqrt{g D s}}{V}$ increases, equilibrium with lower regime bed forms goes hănd in hand with increasing $\mathrm{k}$ or $\left[\frac{\sqrt{g D s} k}{\sqrt{2 T_{v}}}\right]^{1 / 2}$ values and laminar boundary conditions. This continues until a sharp turning point is reached when the boundary conditions below the turbulent eddies switch to being turbulent. The bed becomes unstable and while $\frac{\sqrt{g D S}}{V}$ values remain constant, $\mathrm{k}$ values decrease dramatically until a new turning point is reached, from where upper regime bed forms develop and laminar boundary conditions again dominate.

From Fig. 4 it is clear that for a particular sand particle diameter, as the value of $\frac{\sqrt{g D s}}{V}$ increases, the maximum sand scour ${ }^{\prime s}$ depth that was reached in the cobble-bed scour experiments (as represented by $\Delta$ ) increased in similar fashion to the progression of equilibrium conditions and the associated development of bed forms in a sand-bed river. Furthermore, as is evident in the case of the $0.22 \mathrm{~mm}$ and 0.54 $\mathrm{mm}$ diameter sand particles, Fig. 4 shows that no transition (represented by a sudden decrease in the value of $\Delta$ ) occurred in the case of the cobble-bed river, as opposed to a sand-bed river where transition from lower to upper regime bed forms occurs at a critical value of $\frac{\sqrt{g D s}}{V}$. However, as the 'bed-forms' in a cobble bed are fixed by the exposed cobbles which cannot be washed away, this was expected. Figure 4 therefore confirms the hypothesis that the hydraulic conditions at the point of maximum sand scour along a cobble-bed river are comparable to those that prevail under conditions of dynamic equilibrium in a sand-bed river.

As a final confirmation, the results of the cobble-bed scour experiments were superimposed on a diagram (Fig. 5) which provides a complete averaged picture of the relationship between absolute bed roughness and sand particle characteristics under different flow conditions in an alluvial sand-bed river (Rooseboom and Le Grange, 2000). Again it was found that similar relationships exist between the maximum scour depth in a cobble-bed, and dynamic equilibrium conditions in a sand-bed river, as represented by an increase in the magnitude of $\Delta$. Furthermore, the results indicated that the order of magnitude of the cobble-bed and sand-bed $\Delta$-values are similar up to the point of transition from lower to upper regime bed forms conditions for a sand-

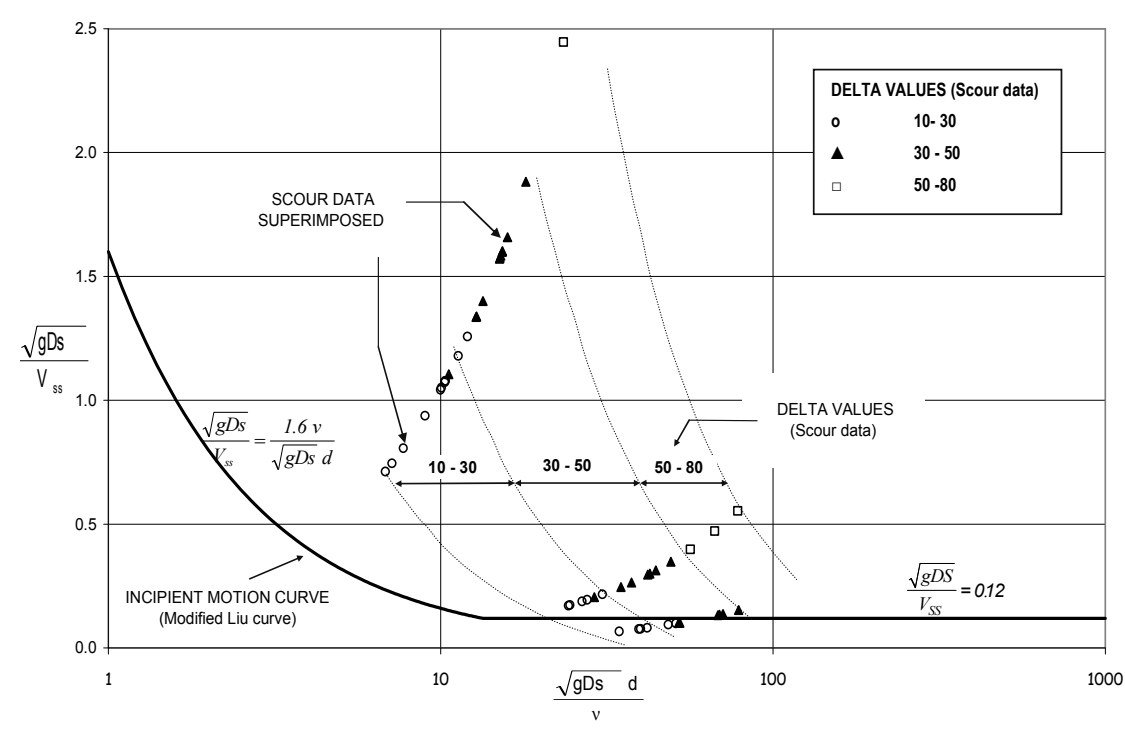

Figure 3

Cobble-bed scour data in relation to critical conditions for cohesionless sediment particles
Figure 4

$\Delta$ values during dynamic equilibrium in a sandbed river with the new cobble-bed scour data superimposed

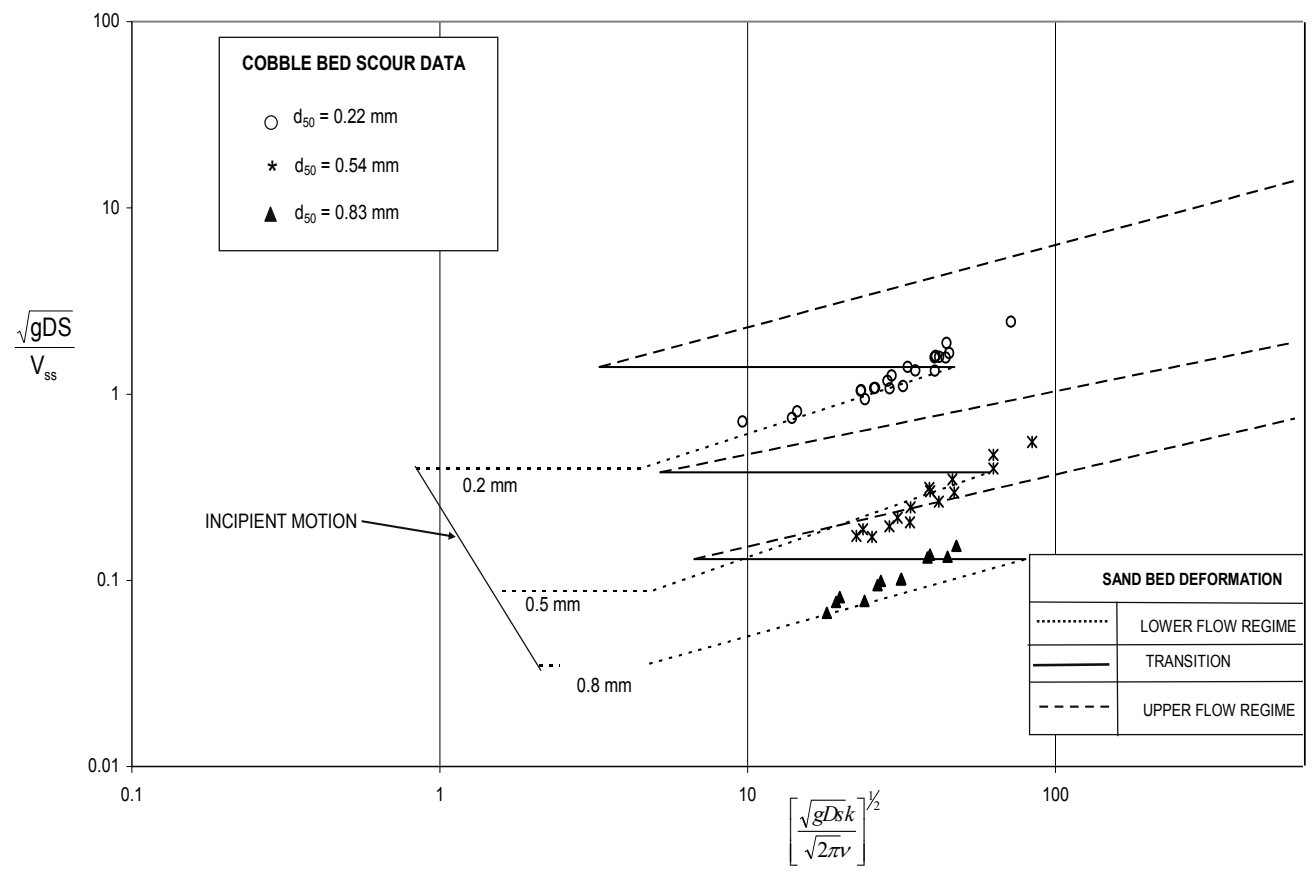




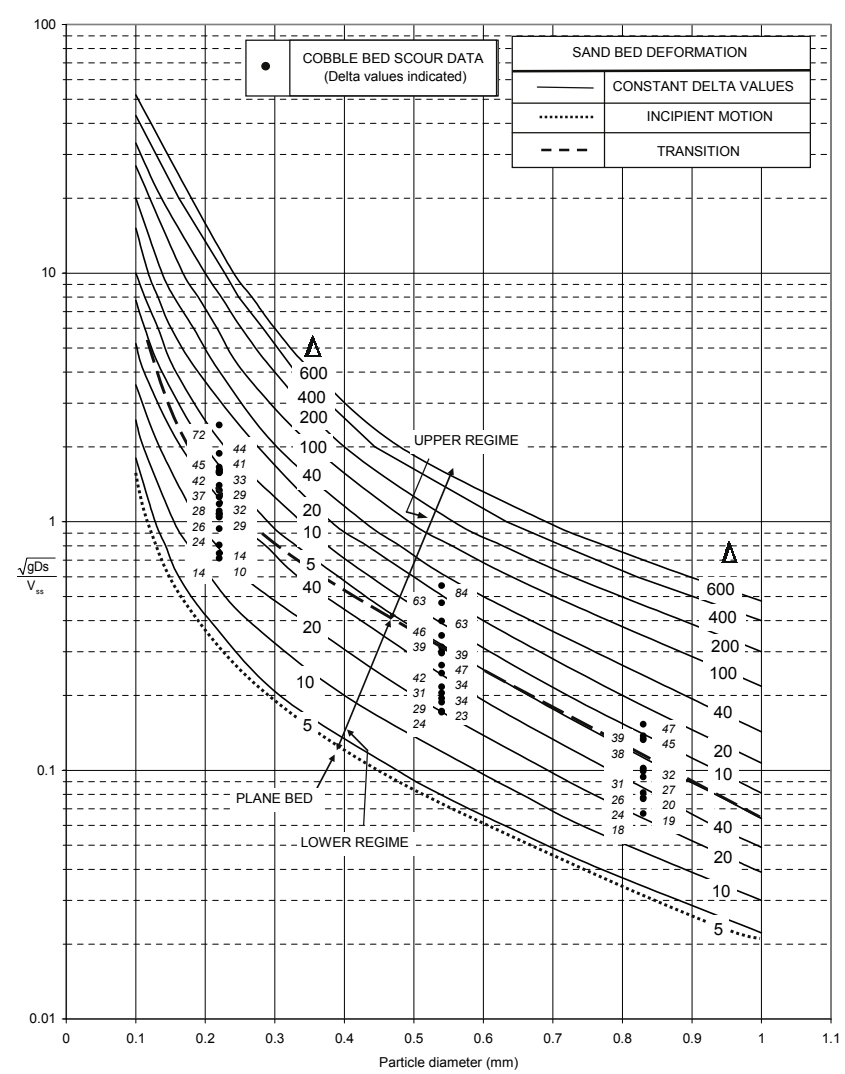

Figure 5

$\Delta$ values and bed-forms in a sand-bed river with the new cobble-bed scour data superimposed

bed river. However, unlike in the case of a sand-bed river where there is a significant reduction in the magnitudes of the $\Delta$-values at this point of transition, the cobble-bed $\Delta$-values show a consistent increase above the 'sand-bed' transition line. This implies that the recorded $\Delta$-values can be extrapolated according to the pattern for sand-bed rivers in order to calculate the discharges required to scour sand from cobble beds down to certain maximum depths.

\section{Conclusions and recommendations}

With the aid of physical model experiments and based on a stream power model which defines the condition of dynamic equilibrium in a deformed sand-bed river, a scour model has been developed to predict the maximum depth of scour of fine sands in a cobble-bed river. In essence, the model defines distinct relationships between absolute bed roughness or maximum scour depth, represented by $\left[\frac{\sqrt{g D S} k}{\sqrt{2 \pi v}}\right]^{1 / 2}$ or $\Delta$, sand particle characteristics and relative applied power $\left(\frac{\sqrt{g D s}}{V}\right)$. The maximum scour depth is the level below the top of the cobbles at which no further scour is observed and is based on average conditions within a cobble-bed area.

The physical model experiments which were used to calibrate the cobble-bed sand scour model were conducted under clear water conditions as the artificial flushing of sediments in practice is likely to be with clear water releases from dams. However, the sand-bed deformation model on which the cobble-bed scour model is based, defines equilibrium under steady state sediment transport conditions. The fact that the relationship between $\Delta$, sand particle characteristics and relative applied power $\left(\frac{\sqrt{g D s}}{V}\right)$ for both of these models is similar, may be ascribed to the fundamental principle on which both models is based. This principle, as described by Eq. (13), states that at the point of dynamic equilibrium in a deformed sand-bed river - or at the point of maximum sand scour in a cobble-bed river - critical conditions for sediment movement prevail at and below an interface between a thin laminar boundary layer along the bed and turbulent eddies above.

The experimental results suggest that, for a specific sand particle diameter, the size of the boundary eddies at critical sediment transport conditions, which reflects the power being applied at the bed and eventually determines maximum scour depth, is not affected by the cobble diameter. It rather seems that the size of the boundary eddies is primarily a function of the absolute scour depth or absolute roughness relative to the top of the exposed cobbles. This implies that the laboratory results may be extrapolated to represent larger scour depths associated with larger cobbles.

It was found that the $\Delta$-values typically range from about 10 to 80 for the range of cobble and sand particle diameters that were tested. Larger cobbles would allow larger scour depths and higher $\Delta$-values at higher values of $\frac{\sqrt{g D s}}{V}$ as is confirmed by Fig. 4, which displays an almost linear increase in the value of delta with increasing values of $\frac{\sqrt{g D s}}{V}$.

It is recommended that further research concentrate on the verification of the cobble-bed sand scour model under field conditions and specifically on how to accommodate the impact of non-uniform cobble sizes. Furthermore, the effect of steady state sediment transport on the calibrated $\Delta$-values needs to be investigated. Finally, the relationship between discharge, sand particle characteristics and the rate of sand scour needs to be determined in order that not only the magnitude but also the duration of the flushing flow may be quantified, both of which are critical for developing the theoretical model into a practical applied methodology.

\section{Acknowledgement}

The authors are indebted to the South African Water Research Commission (WRC) for providing financial assistance.

\section{References}

GORDON NC, McMAHON TA and FINLAYSON BL (1992) Stream Hydrology - An Introduction for Ecologists. John Wiley and Sons, England. 444 pp.

GRAF WH (1971) Hydraulics of Sediment Transport. McGraw-Hill, New York. 513 pp.

GRASS AJ (1970) The initial instability of fine sand. ASCE Proc. J. Hydraul. Div. 96 (HY3) 619-632.

HIRSCHOWITZ PM, BIRKHEAD AL and JAMES CS (2007) Hydraulic Modelling for Ecological Studies for South African Rivers. WRC Report No. 1508/1/07. Water Research Commission, Pretoria, South Africa.

JONKER V (2002) Environmentally Significant Morphological and Hydraulic Characteristics of Cobble and Boulder Bed Rivers in the Western Cape. Ph.D. Thesis. University of Stellenbosch, Stellenbosch, South Africa.

KONDOLF GM and WILCOCK PR (1996) The flushing flow problem: Defining and evaluating objectives. Water Resour. Res. 32 (8) 2589-2599.

LIGON FK, DIETRICH WE and THRUSH WJ (1995) Downstream ecological effects of dams, a geomorphic perspective. Biosci. 45 (3) 183-192.

LIU HK (1957) Mechanics of sediment-ripple formation. ASCE Proc. J. Hydraul. Div. 83 (HY2) 1-23.

REISER DW, RAMEY MP and WESCHE TA (1989) Flushing flows. 
In: Gore JA and Petts GE (eds.) Alternatives in Regulated River Management. CRC Press, Boca Raton, Florida, USA. 386 pp.

ROOSEBOOM A (1974) Open Channel Fluid Mechanics. DWAF Technical Report No. 62. Department of Water Affairs and Forestry, Pretoria, South Africa.

ROOSEBOOM A (1992) Sediment Transport in Rivers and Reservoirs - A South African Perspective. WRC Report No. 297/1/92. Water Research Commission, Pretoria, South Africa.

ROOSEBOOM A (1998) The Cinderella of hydraulics - the law of conservation of power. Proc. $3^{\text {rd }}$ Intl. Conf. Hydrosci. Eng. Cottbus, Germany. 1-14.
ROOSEBOOM A and LE GRANGE A (1994) Equilibrium scour in rivers with sand beds. Proc. $2^{\text {nd }}$ Int. Conf. River Flood Hydraulics. York, England. 321-334

ROOSEBOOM A and LE GRANGE A (2000) The hydraulic resistance of sand streambeds under steady flow conditions. J. Hydraul. Res. 38 (1) 27-35.

WILCOCK PR, KONDOLF GM, MATTHEWS WVG and BARTA AF (1996) Specification of sediment maintenance flows for a large gravel-bed river. Water Resour. Res. 32 (9) 2911-2921.

YANG CT (1973) Incipient motion and sediment transport. ASCE Proc. J. Hydraul. Div. 99 (HY10) 1679-1704. 
Available on website http://www.wrc.org.za ISSN 0378-4738 = Water SA Vol. 34 No. 3 July 2008

ISSN 1816-7950 = Water SA (on-line) 